\title{
Implementasi Keterlibatan Mahasiswa Dalam Analisis Mengenai Dampak Lingkungan Hidup Sebagai Perwujudan Kesadaran Lingkungan
}

\author{
Marlina Dea Nur Cahyanti ${ }^{1}$, Rika Putri Handriyanti ${ }^{2}$, Kris Yunianto ${ }^{3}$, Anita Trisiana ${ }^{4}$ \\ ${ }^{1}$ Mahasiswa PPKn Universitas Slamet Riyadi Surakarta \\ ${ }^{2}$ Dosen PPKn Universits Slamet Riyadi Surakarta
}

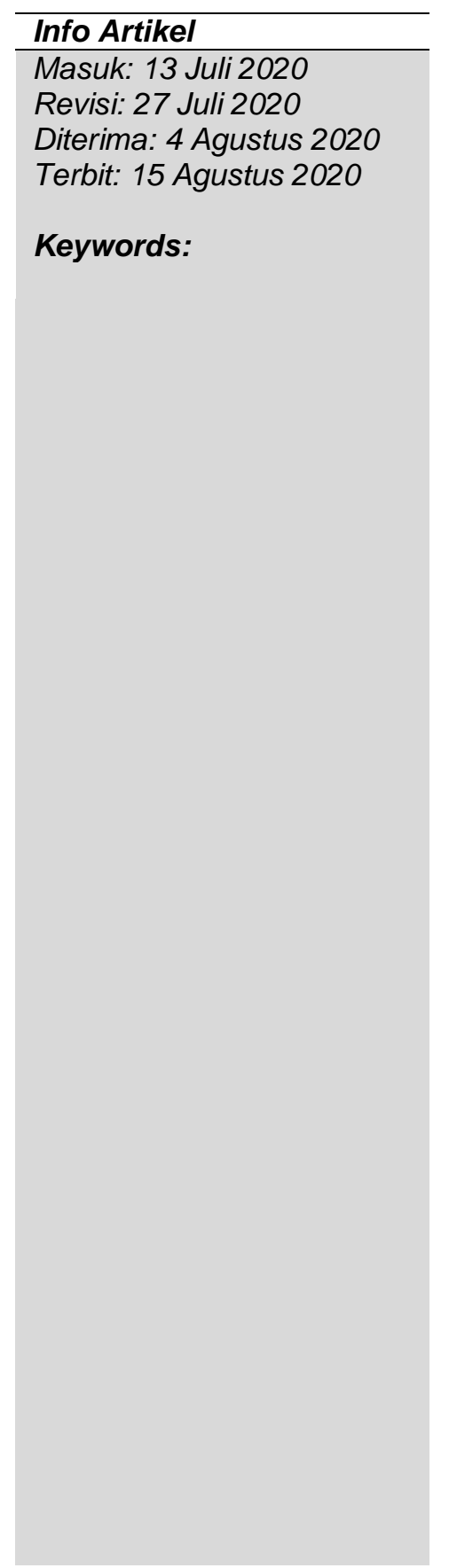

\begin{abstract}
The analysts the impact of environmental the is a study on the impact of positive or negative of a project plans, used by the government to decide whether activities and projects were suitable environment .The purpose of the report is to ensure an activity and projects can run sustainable without damaging environment . Because with the amdal expected an activity and projects can use or manage natural resources effectively and efficient by means of maximize the impact of positive and minimize the impact of out the negatives . A huge amount of damage and environmental benefits when it is getting really bad for example, the damage to coral reefs, result of water pollution, air pollution as well as, are prone to air pollution caused by garbage during this complex. As some say it is also a form of human behaviour that is not satisfied and did not keep environment optimally. Progress is being made in the technology and discovery the odor of at the time of this covenant averse from its very for the survival of human life .All activities more is easy to do and is practically, but the utilization of the invention that unlocked drawn too much to the survey specifically in plastic that yet they created to accommodate an object the aga is easy to carry every where, and it will make hill corruption caused by monetary policies clean up the trash that the part of a car, and electronic. Since the 1950s plastic becomes an important part of in human life .Plastic used as raw materials for packaging, textile, bag, excelent of plastic that praktis, wanna, easy to find and also muah is facto sector-wide policy man surroundings chemicals that give rise to a complex problem about emerge when disadai that plastic is not tedegadasi even though $i$ was tependam inside the ground in a period of a very long time .From it then sevagai pollution response by the presence of a
\end{abstract}




\section{Kata kunci:}

P-ISSN : 2550-0171

E-ISSN : $2580-5819$

DOI : 10.33061 student to be garbage, students should be an example and reformer for the environment around .

\section{Abstrak}

Analis Mengenai Dampak Lingkungan Hidup (AMDAL) merupakan suatu kajian mengenai dampak positif atau negative dari suatu rencana kegiatan/proyek,yang digunakan oleh pemerintah untuk memutuskan apakah kegiatan/proyek tersebut layak lingkungan. Tujuan AMDAL adalah untuk menjamin suatu kegiatan/ proyek dapat berjalan secara berkesinambungan tanpa merusak lingkungan hidup. Olehs ebab itu dengan adanya amdal diharapkan suatu kegiatan/ proyek dapat memanfaatkan atau mengelola sumber daya alam dengan efektif dan efisien dengan cara memaksimalkan dampak positifnya dan meminimalkan dampak negatifnya. Kerusakan lingkungan saat ini semakin parah misalnya, kerusakan terumbu karang, pencemaran air, pencemaran udara, pencemaran yang disebabkan oleh sampah saat ini sangat kompleks. Hal itu adalah juga merupakan ulah manusia yang tidak pernah puas dan tidak menjaga lingkungan dengan baik. Kemajuan tekhnologi dan penemuan-penemuan bau saat ini memanglah sangat bemanfaat bagi kelangsungan hidup manusia. Segala kegiatan lebih mudah dilakukan dan praktis,namun pemanfaatan penemuan yang telalu banyak khususnya plastik yang notabene di ciptakan untuk menampung suatu benda agar mudah dibawa kemana-mana malah menimbulkan bukitbukit sampah yang bewana bagian-bagian mobil, dan alat-alat elektonik. Sejak tahun 1950-an plastik menjadi bagian penting dalam kehidupan manusia. Plastik digunakan sebagai bahan baku kemasan, tekstil, Keistimewaan plastik yang praktis,ringan,mudah ditemukan dan juga muah adalah fakto manusia menggemai bahan kimia yang menimbulkan pemasalahan lingkungann yang kompleks. Pesoalan muncul ketika disadari bahwa tena plastik tidak dapat terdegradasi meskipun telah tependam didalam tanah dalam jangka waktu 
yang sangat lama. Dari hal itu maka sebagai mahasiswa harus tanggap dengan adanya pencemaran sampah, mahasiswa harus menjadi teladan dan pembaharu bagi lingkungan sekitar.

\section{PENDAHULUAN}

Mengenai Dampak Lingkungan Hidup (AMDAL) merupakan suatu kajian mengenai dampak positif atau negative dari suatu rencana kegiatan/proyek,yang digunakan oleh pemerintah untuk memutuskan apakah kegiatan/proyek tersebut layak lingkungan.Pengertian AMDAL menurut PP No.27 Tahun 1999. Oleh sebab itu dengan adanya amdal diharapkan suatu kegiatan/ proyek dapat memanfaatkan atau mengelola sumber daya alam dengan efektif dan efisien dengan cara memaksimalkan dampak positifnya dan meminimalkan dampak negatifnya

Dalam menghadapi pencemaran lingkungan Pemerintah mengeluarkan PP No. 27 Tahun 1999 tentang Analisis Mengenai Dampak Lingkungan Hidup (AMDAL). Berbagai bencana Lingkungan hidup bergantian, mulai pencemaran lingkungan, kerusakan lingkungan, rusaknya terumbu karang, eksploitasi tanah dan lain

sebagainya, yang semakin mengkhawatirkan. Hal ini berkaitan dengan perilaku manusia yang menempatkan alam sebagai komoditas yang dieksploitasi tanpa menghiraukan daya dukung lingkungan yang bisa mengalami degradasi. Manusia adalah makhluk yang serakah yang mana tidak pernah puas dengan apa yang dia miliki. Sumber daya alam adalah sasarannya , banyak manusia berlomba-lomba mengeksploitasi sumbe daya alam tanpa memikikan dampak yang telah mereka perbuat. Selain itu Seiring perkembangan jaman dan modernisasi dalam bidang tekhnologi yang awalnya dimanfaatkan agar hidup manusia menjadi lebih mudah dan praktis tetapi jika penggunaannya berlebihan maka akan merusak lingkungan hidup juga.

Lingkungan hidup merupakan kesatuan antara makhluk hidup ,benda-benda dan bahkan perilaku manusia yang ada dan termasuk didalamnya. lainnya(pof.d.ju.andihamzah,2008, penegakan hukum lingkungan,jakata,suna gafik.. Menut emil salim,lingkungan hidup diartikam sebagai benda, kondisi, keadaan, dan pengaruh yang terdapat dalam ruang yang kita tempati dan mempengaruhi hal yang hidup termasuk kehidupan manusia sedangkan otto soemawanto berpendapat bahwa lingkungan hidup merupakan semua benda dan kondisi yang ada dalam ruang kita. 


\section{METODE PENELITIAN \\ PEMBAHASAN}

Limbah sampah sudah menjadi hal yang biasa bagi kehidupan manusia. Dalam kehidupan sehari-hari manusia memerlukan banyak material dan semua material tesebut berakhir sebagai sampah. Meskipun beberapa orang sadar akan dampak lingkungan tetapi mereka tetap saja menciptakan sampah hanya saja jumlahnya yang lebih sedikit.

Kemajuan tekhnologi dan penemuan-penemuan baru saat ini memanglah sangat bermanfaat bagi kelangsungan hidup manusia. Segala kegiatan lebih mudah dilakukan dan praktis,namun pemanfaatan penemuan yang terlalu banyak khususnya plastik yang notabene di ciptakan untuk menampung suatu benda aga mudah dibawa kemana-mana malah menimbulkan bukit-bukit sampah yang bewarna warni, Dalam dunia kedokteran plastik juga dimanafaatkan untuk mengganti bagian-bagian tubuh manusia yang tidak berfungsi lagi. Plastik petama kali di perkenalkan oleh alexande pakes pada tahun 1862 disebuah ekshibisi international di london, inggris yang dibuat dari bahan oganik dai selulosa. Sayangnya temuannya ini tidak dapat memasyarakat dikarenakan bahan bakunya yang mahal. Lalu pada tahun 1866, seseoang yang berasal dari amerika bernama john wesley hyatt,menemukan bahwa seluloid

Plastik sudah menjadi bagian paling penting bagi kehidupan manusia karena praktis, ringan, mudah ditemukan dan juga murah adalah fakta manusia menggemari bahan kimia yang menimbulkan permasalahan lingkungann yang kompleks. Persoalan muncul ketika disadari bahwa tena plastik tidak dapat terdegradasi meskipun telah terpendam didalam tanah dalam jangka waktu yang sangat lama (isananto winusito, pekembangan penelitian plastik biodegadabel di nindonesia.2013, balai iset dan standadisaasi industi manado,junal)

Hasil studi university of geogia,china adalah negara konsumen plastik terbesar di dunia. Anatara 11,5 juta ton sampah plastik pe tahunnya,sebanyak $78 \%$ diantaanya akan lari kelaut setiap tahunnya. Jika dihitung setiap masyarakat diwilayah pesisir cina membuang 33,6 kilogam plastik kelaut pertahunnya. Lalu bagai mana dengan indonesia? di hitung dai persentase jumlah sampah plastik yang tidak diolah,indonesia termasuk yang paling tinggi di dunia. Sebayak $87 \%$ dai sampah yang ada dilaut sebanyak 3,8 juta , maka dari itu setiap tahun penduduk pesisir di indonesia bertanggung jawab atas 17,2 kilogam sampah plastik yang mengapung di lautan. di ambil pada tanggal 13 novembe 2018) 
Pada kenyataannya manusia sendirilah yang menciptakan lingkungan itu menjadi bersih ataupun tidak. .Tapi pada kenyataannya masih banyak manusia-manusia yang tidak bertanggung jawab karena telah membuang sampah sembarangan,jika dalam satu hari ada 1 manusia yang membuang sampah sembarangan sebanyak 10 lembar plastic saja,dan jika di kalikan dengan jumlah penduduk di Indonesia mencapai 265 juta jiwa (dikutip dari katadata.co.id) maka dalam satu tahun Indonesia dapat tertutup oleh sampah plastic. Tentu saja hal ini dapat merusak lingkungan yang pada dasarnya sampah plastic adalah sampah yang paling sulit untuk diurai tanah. Sampah merupakan momokmbagi masayrakat, wlaupun sering kali dianggap sebagai hal yang sederhana namun ternyata bahaya sampah bagi kelangsungan kehidupan sangat berpengaruh terhadap kualitas lingkungan. Smakin hari semakin banyak sampah yang menumpuk, maka dari itu untuk mengurangi pencemaran sampah maka sebaiknya kita sebagai mahasiswa membuat gerakan untuk menjadi teladan di masyrakat.

\section{Solusi Efektif Untuk Mengatasi Sampah Plastik}

Langkah-langkah dalam mengurangi pencemaran sampah Plastik

Tentu kita sehari-hari tidak luput dari penggunaan plastik mulai dari untuk bungkus makanan, minuman, tas belanja, dan lain-lain. Plastik sudah tidak asing bagi kita, namun ada beberapa hal yang dapat mengurangi penggunaan plastik dengan cara life without plastic yaitu hidup tanpa plastik:

-Membawa tas belanja sendiri yang berbahan dari kain yang mudah terurai

-Membawa botol minuman sendiri.

-Menggunakan lunch box sebagai pengganti wadah seperti mika, plastik makanan untuk tempat makan atau bekal.

-Stop memakai sedotan dan sendok sekali pakai.

-Menyimpan sisa makanan didalam tempat yang berbahan dari kaca sehingga menggatikan fungsi plastik dan juga tidak mudah busuk.

-Memanfaatkan plastik sebagai bahan kerajinan tangan.

\section{KESIMPULAN}


Sampah plastik mulai memburuk, dan permasalahan semaki kompleks, banyak dampak yang ditimbulkan dari adanya sampah plastik ini.

Oleh karena itu, sebagai mahasiswa kita harus sadar dan mengajak masyarakat untuk tetap sadar akan bahaya sampah plastik dan mencegah sampah plastik menjadi momok bagi kehidupan, yaitu dengan cara memanfaatkan sampah plastik dan juga mencari alternatif lainnya untuk mengganti plastik dengan bahan yang mudah terurai.

\section{Saran}

1.Bagi pembaca : diharapkan karya esai ini dapat memberikan wawasan dan mampu membuat kita sadar akan setiap bahaya plastik.

2. Bagi Pemerintahan : mengadakan pelatihan- pelatihan dengan memanfaatkan sampah plastik supaya lebih berguna dan menjadi barang dengan nilai jual tinggi.

\section{DAFTAR PUSTAKA}

Absori, Khudzaifah Dimyati dan Ridwan, 2017. Makna dan Pengeolaan Lingkungan, Perspektif Etik Propetik”, Jurnal At-Tahrir STAIN Ponorogo.

Fidelis, Achuba, 2014. Effect of Environmental Pollution on Oxidative Stress in African Catfish, Nigeria: PMBI Abraka Nigeria.

Fitria, 2014. Sanksi Administrasi Terhadap Analisis Lingkungan( AMDAL) Dalam Sistem Penegakan Hukum Lingkungan, Jambi

Harris, P \& Francessa Viliani, 2015. Assesinga Health Impacts within Environmental Impact Assesment:An Opportunity for Public Health Globally Which Must Not Remain Missed, Sidney Australia

Hozdie, Elvis, 2015. Smart Factory For Industry 4,0:Review, Slovenia: University of Ljubljana.

Isananto winusito, 2013. pekembangan penelitian plastik biodegadabel di Indonesia. balai iset dan standadisaasi industi manado,junal)

Kemal, Mustafa Ramadhan, 2015. Implementasi Keterlibtaran Masyarakat dalam Analisis Mengenai Dampak Lingkungan Hidup, Semarang : Unnes 
Mardika, Wati, 2015. Pencemaran di Sungai Akibat Pembangunan Limbah Industri Pabrik Tahu, Kudus : Universitas Muhamamdiyah Yogyakarta.

Prof.d.ju.andi hamzah, 2008. Penegakan Hukum Lingkungan, Jakata,Suna Gafika.

Soermarmoto Otto, 1994. Ekologi, Lingkungan Hidup dan Pembangunan, Jakarta,Djamba 